http://journal.uin-alauddin.ac.id/index.php/lamaisyir

Publisher: Fakultas Ekonomi dan Bisnis Islam UIN Alauddin Makassar

\title{
IMPLEMENTATION OF IJARAH IN EFFORTS TO IMPROVE FARMER WELFARE
}

\author{
Ninit Firdayanti1, Renny Oktafia ${ }^{2}$ \\ 1,2Universitas Muhammadiyah Sidoarjo \\ 1,2Jl. Mojopahit 666 B Sidoarjo \\ firdayanti20041998@gmail.com¹, Renny.oktafia@umsida.ac.id²
}

Received: 23 September 2020; Revised: 24 September 2020; Published: 05 Desember 2020

\begin{abstract}
ABSTRAK
Lahan pertanian memiliki lahan yang luas dan bermanfaat bagi petani, akan tetapi tidak semua penduduk desa bekerja sebagai petani karena keterbatasan dana dan membutuhkan uang, sehingga lebih memilih untuk disewakan. Tujuan penelitian ini untuk mengetahui penerapan akad ijarah serta dampak pada sektor pertanian. Penelitian ini menggunakan metode kualitatif dengan menerapkan pendekatan studi kasus yang bertujuan untuk mendapatkan informasi secara langsung dari informan berdasarkan kasus yang sedang terjadi. Hasil penelitian ini menunjukkan bahwa penerapan sewa lahan pertanian di Desa Garung sesuai dengan hukum Islam serta ada beberapa informan perbedaan penjelasan terkait nominal biaya ujrah, tahun dan berakhirnya perjanjian sewa lahan pertanian, sedangkan untuk dampak bagi petani pemilik lahan tidak dapat meningkatkan kesejahteraan dari indikator agama dan jiwa tetapi dalam segi penyewa lahan dapat meningkatkan kesejahteraan dari indikator agama, jiwa, akal, keturunan, dan harta.
\end{abstract}

Kata kunci: Perjanjian Sewa; Kesejahteraan; Lahan Pertanian.

\begin{abstract}
Agricultural land has a large area and is useful for farmers, but not all villagers work as farmers due to limited funds and need money, so they prefer to rent it. This study aimed to determine the application of the ijarah contract and its impact on the agricultural sector. This study uses a qualitative method by applying a case study approach to obtain information directly from informants based on current cases. This study indicates that the application of agricultural land leases in Garung Village is following Islamic law. Several informants differ in explanations regarding the nominal fee of ujrah, year, and the expiration of agricultural land lease agreements. At the same time, the impact on landowners cannot improve welfare from religious indicators and souls. Still, it can improve welfare from indicators of religion, life, mind, descent, and property in terms of land tenants.
\end{abstract}

Key words: Lease Agreement; Well-being; Agricultural land. 
Ninit,: Lease Agreement; Well-being; Agricultural land.

\section{PENDAHULUAN}

Indonesia merupakan Negara agraris kaya hasil perolehan sumber daya alam terutama pada sektor pertanian. Pada tanggal 8 Oktober 2018 Keputusan Menteri/Kepala BPN No.399/kep-23.3/X/2018 menetapkan bahwa luas lahan baku nasional tercatat sebesar 7.105.000 hektar, sedangkan angka tersebut mengalami peningkatan dengan jumlah 358.948 hektar, sehingga pada tahun berikutnya tanggal 17 Desember 2019 Keputusan Menteri/Kepala BPN No.686/SK-PG.03.03/XII/2019 menetapkan bahwa luas lahan baku nasional tercatat sebesar 7.463.948 hektar (Badan Pusat Statistik Provinsi Jawa Timur, 2020).

Indonesia disebut sebagai Negara agraris karena sebagian besar penduduk Indonesia berkerja disektor pertanian, khususnya masyarakat pedesaan yang mana mata pencahariannya sebagai petani (Alitawan \& Sutrisna, 2017). Indonesia memiliki luas lahan pertanian yang merupakan modal utama dalam bercocok tanam, meskipun memiliki luas lahan pertanian yang luas tetapi masih belum dapat mencapai suatu keberhasilan usaha petani dalam meningkatakan produktivitas, maka diperlukannya sumber daya manusia yang memadai (Suratha, 2015).

Sektor pertanian merupakan sektor yang dapat mengelolah dan memanfaatkan hasil panen yang berhubungan dengan komoditas pangan (Isbah \& Iyan, 2016). Sektor pertanian bagi kehidupan masyarakat Indonesia sangat dibutuhkan karena dapat menghasilkan bahan pangan untuk menunjang kebutuhan pangan dalam kehidupan sehari-hari, dan juga sebagai bahan baku industri, sumber tenaga kerja, serta mengurangi tingkat kemiskinan (Nugraha, 2016). Penduduk desa yang bekerja disektor pertanian dapat meningkatakan perekonomian khususnya bagi peningkatan kesejahteraan dari segi materi (Oktafia, 2016). Hal ini diperkuat dengan adanya Dasar Hukum Peraturan Pemerintah No.65 tahun 2019 terkait Jaminan Luasan Lahan Pertanian yang menyatakan bahwa lahan pertanian bagi masyarakat Indonesia memiliki peran strategis yang bercorak agraris dan sebagian besar penduduknya bercocok tanam dalam sektor pertanian.

Lahan pertanian yang subur akan mengasilkan produksi padi melimpah disetiap provinsi, dimana provinsi jawa timur mendapatkan peringkat kedua atas perolehan hasil padi. Pada tahun 2018 produksi padi tercatat senilai 10.203.213 ton, sedangkan tahun berikutnya mengalami penurunan senilai 622.279 ton, sehingga pada tahun 2019 produksi padi 
menjadi 9.580.934 ton (Badan Pusat Statistik, 2020). Sektor pertanian di Indonesia dapat meningkatkan perekonomian masyarakat dan dapat menciptakan kesejahteraan terutama bagi penduduk desa (Setiawan, 2015).

Kesejahteraan merupakan kondisi terpenuhinnya suatu kebutuhan dari setiap orang sesuai dengan standar yang ada dilingkungan masingmasing (Ridho, 2017), sedangkan kesejahteraan petani merupakan kondisi dari setiap masing-masing orang yang bertujuan untuk memenuhi suatu kebutuhan pokok dalam rangka mencapai taraf hidup baik individu atau kelompok, sehingga dapat menjalankan aktivitas normal ditengah penduduk desa yang mayoritas sebagai seorang petani. (Rachmat, 2013). Kesejahteraan agar dapat dicapai secara adil dan tidak merugikan banyak orang, maka dalam Islam diatur adanya prinsip menumbuhkan kemaslahatan dan menjauhi perilaku kemudharatan (Sholihin, Ami'in, \& Lestari, 2019). Kesejahteraan dapat dipadukan dengan unsur-unsur maqashid syariah yang dapat memberikan kemaslahatan bagi kehidupan manusia baik didunia maupun diakhirat yang terdiri dari hifdz din, hifdz al-nafs, hifdz 'aql, hifdz an-nasab, hifdz maal (Nasution \& Nasution, 2020).

Pada data Badan Pusat Statistik Provinsi Jawa Timur menyatakan bahwa Provinsi Jawa Timur terdiri dari 38 Kabupaten atau kota. Diantara beberapa Kabupaten yang ada di Provinsi Jawa Timur, terdapat satu kabupaten yang memiliki luas lahan pertanian yang paling luas yaitu Kabupaten Lamongan dengan luas lahan pertanian sebesar 5.033,99 m2 yang terbagi menjadi berbagai jenis lahan seperti luas sawah irigasi sebesar 1.636,38 $\mathrm{m} 2$, luas sawah non irigasi sebesar 2.027,67 m2, luas lahan bukan sawah sebesar 1.178,15 m2, dan luas lahan bukan pertanian sebesar 191,54 m2 (Badan Pusat Statistik Provinsi Jawa Timur, 2019).

Lahan pertanian memiliki manfaat yang besar bagi petani yaitu sebagai penghasil bahan pangan baik untuk dikonsumsi sendiri maupun untuk dijual (Utomo \& Wulandari, 2020). Namun tidak semua masyarakat penduduk bekerja sebagai petani karena adanya suatu keterbatasan dana sehingga penduduk tersebut lebih memilih untuk bekerja dibidang sektor yang lain seperti: tukang bangunan, buruh tani, buruh pabrik dan pedagang. Kemudian penduduk tersebut lebih memilih untuk menyewakan lahan pertanian mereka kepada orang lain yang memiliki uang lebih (Fawa'id \& Huda, 2020). Begitu juga sebaliknya penduduk yang memiliki uang lebih mereka memilih untuk menyewa lahan pertanian sebagai mata pencaharian utama mereka.

Sewa lahan pertanian ini banyak diterapkan di pedesaan, seperti Desa Garung yang mayoritas penduduk bekerja sebagai petani. Sewa menyewa 
disebut al-Ijarah yang berasal dari kata al-ajru yang berarti al-'iwadh yang memiliki arti ganti dan upah (Suhendi, 2016). Ijarah adalah suatu akad pemindahan manfaat atas barang atau jasa tanpa adanya keikut sertaan dalam pemindahan kepemilikan barang itu sendiri dengan melalui pembayaran upah sewa (Umam, 2013). Akad ijarah dari sisi objek disebut dengan ijarah almanfa'ah (Amalia, 2015). Transaksi akad ijarah dalam Islam diperbolehkan sebagaimana Allah berfirman dalam Qs. Qasas (28) ayat 26:

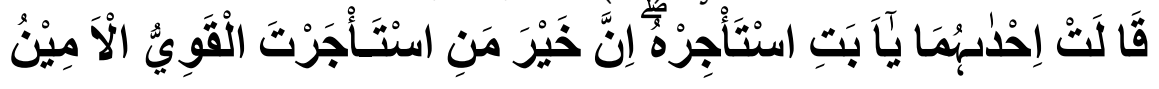

Terjemahnya:

"Salah seorang dari kedua wanita itu berkata: "Ya bapakku ambillah ia sebagai orang yang bekerja (pada kita), karena sesungguhnya orang yang paling baik yang kamu ambil untuk bekerja (pada kita) ialah orang yang kuat lagi dapat dipercaya".

Pembayaran sewa dan upah dalam ijarah al-manfa'ah diwajibkan membayar uang sewa ketika kesepekatan perjanjian akad (Suhendi, 2016). Akad ijarah memiliki kemungkinan terjadinya pembatalan dan berakhirnya suatu akad disebabkan meninggalnya dari salah satu pihak yang berakad, tercapainya kepuasan atas manfaat barang yang disewakan oleh pihak penyewa, dan berakhirnya masa waktu perjanjian yang ditentukan oleh kedua pihak (Santoso \& Anik, 2015).

Pada data profil Desa Garung, Desa Garung merupakan sebuah desa yang berada di Kecamatan Sambeng Kabupaten Lamongan. Desa Garung memiliki luas wilayah sebesar $110 \mathrm{~km}^{2}$ dan memiliki kepadatan jumlah penduduk sebesar 2.232 jiwa. Alasan peneliti melakukan penelitian di Desa Garung karena banyak penduduk menerapkan sewa lahan pertanian yang disebabkan tidak memiliki keahlian dalam mengelola lahan pertanian dan membutuhkan uang sehingga memutuskan untuk menyewakan lahan pertaniannya, disamping itu banyaknya penduduk Desa Garung yang mayoritas bekerja sebagai petani yang dibuktikan dari data jumlah penduduk berdasarkan pekerjaan yang menyatakan bahwa pekerjaan terbanyak didominasi oleh pekerjaan petani dengan jumlah sebesar 781 jiwa penduduk laki-laki, sedangkan 648 jiwa penduduk perempuan.

Permasalahan yang kerap terjadi dalam pelaksanaan sewa lahan pertanian di Desa Garung Kecamatan Sambeng Kabupaten Lamongan yaitu sewa lahan pertanian yang dilakukan secara tidak tertulis, tidak ada pihak 
ketiga yang ikut menyaksikan perjanjian sewa lahan pertanian, dan kebanyakan mereka sering kali lupa dengan tahun antara pelaksanaan awal perjanjian dengan tahun berakhirnya masa perjanjian sewa lahan pertanian. Maka fokus dari penelitian ini yaitu mengenai implementasi akad ijarah pada sektor pertanian dan dampak bagi peningkatan kesejahteraan petani yang dapat dirasakan oleh petani.

\section{METODE PENELITIAN}

Metode penelitian yang digunakan adalah penelitian kualitatif dengan pendekatan studi kasus. Tujuan peneliti menggunakan pendekatan studi kasus adalah untuk memusatkan satu objek yang diangkat sebagai sebuah kasus dengan mengamati informan secara langsung yang melakukan sewa lahan pertanian. Jenis data yang digunakan adalah primer dan sekunder, diperoleh dari hasil wawancara yang dilakukan oleh peneliti kepada 17 informan yang melakukan sewa lahan pertanian serta buku profil Desa Garung.

Teknik pengumpulan data pada penelitian menggunakan observasi partisipasi pasif, wawancara secara terstruktur yang dilakukan dimalam hari dengan mendatangi kesetiap rumah informan, serta dokumentasi sebagai data pendukung. Teknik analisis data pada penelitian ini menggunakan model Miles dan Huberman dengan menggunakan tiga tahap, tahap pertama reduksi data dengan merangkum data dari hasil penelitian. Tahap kedua penyajian data diperoleh dari kumpulan seluruh informasi dari hasil lapangan yang sudah tersusun. Tahap ketiga penarikan kesimpulan digunakan untuk jawaban setiap masalah yang diteliti. 


\section{HASIL PENELITIAN DAN PEMBAHASAN}

\section{Keadaan Sosial Ekonomi dan Potensi Sumber Daya Alam di Desa Garung}

Desa Garung merupakan sebuah pemukiman desa yang berdiri sejak tahun 1926 dengan luas wilayah sebesar $110 \mathrm{~km}^{2}$, yang dikelilingi hutan jati dengan luas $625 \mathrm{~km}^{2}$. Letak wilayah Desa Garung berada di Kecamatan Sambeng Kabupaten Lamongan, dengan total jumlah penduduk sebesar 2.232 jiwa yang meliputi jumlah penduduk laki-laki sebesar 1.113 jiwa, jumlah penduduk perempuan 1.119 jiwa, jumlah penduduk pendatang sebesar 20 jiwa, jumlah penduduk pergi sebesar 43 jiwa. Adapun grafik mata pencaharian penduduk Desa Garung.

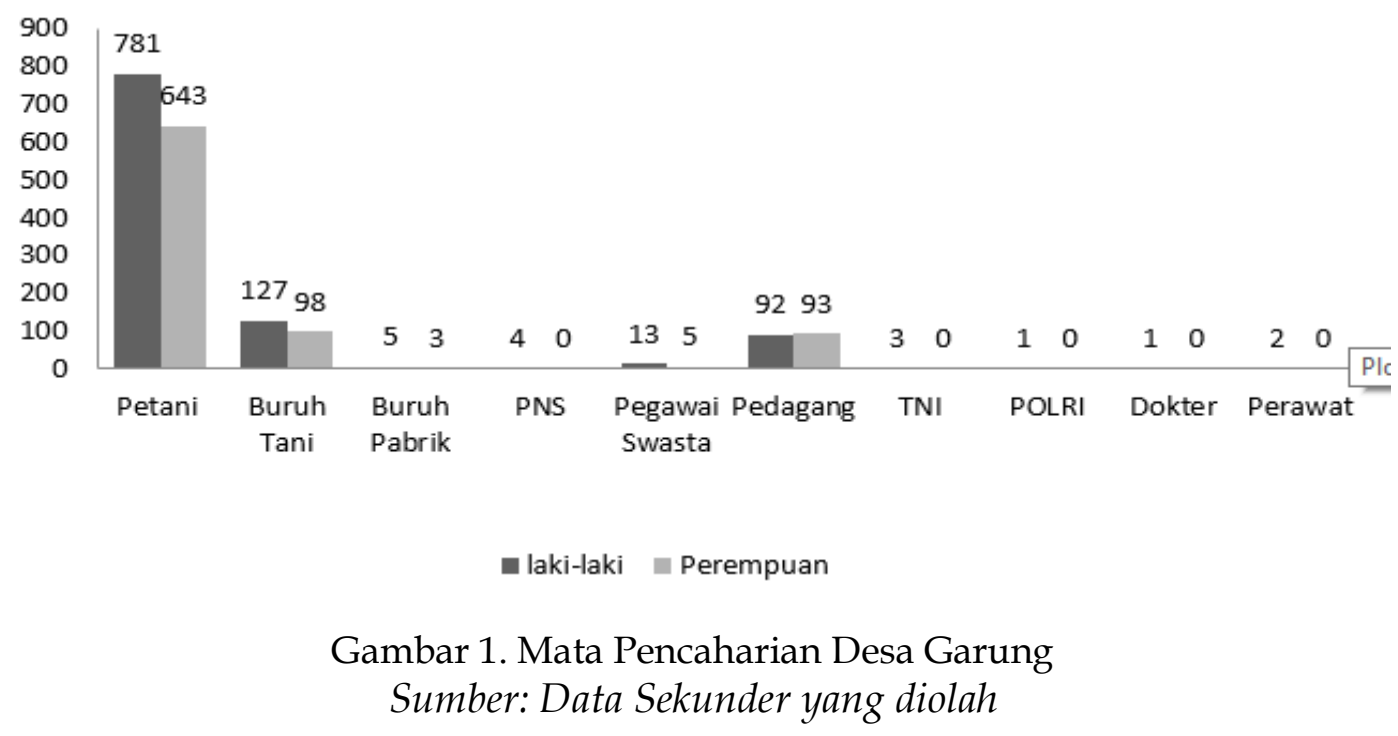

Hasil dari data grafik dapat menunjukkan bahwa jumlah pekerjaan terbanyak didominasi oleh sektor pertanian, dimana mayoritas penduduk Desa Garung bekerja sebagai petani. Menurut ibu Dwi Estuning Hidayah selaku Koordinator Balai Penyuluhan Dinas Pertanian Kecamatan Sambeng mengatakan bahwa potensi sumber daya alam di Desa Garung sebagian besar dipergunakan sebagai lahan pertanian dengan memiliki luas tanah sawah sebesar 132,30 hektar, luas tegal sebesar 57,99 hektar. Menurut bapak Roikhanus Sholih selaku sekretaris desa mengatakan bahwa lahan pertanian di Desa Garung mayoritas ditanami dengan padi, jagung, tembakau, dan tebu. Banyaknya penduduk yang bekerja sebagai petani dan terkadang ada penduduk yang membutuhkan uang sehingga harus menyewakan lahan 
pertanian tersebut kepada kerabat atau tetangga rumah, tetangga sawah. Banyak penduduk yang melakukan akad ijarah pada lahan pertanian, akan tetapi belum ada catatan yang valid terkait dengan jumlah berapa banyak penduduk yang menerapkan akad ijarah pada lahan pertanian yang ada di Desa Garung.

\section{Implementasi Akad Ijarah pada Sektor Pertanian di Desa Garung}

Implementasi akad ijarah pada sektor pertanian di Desa Garung menggunakan proses pengolahan data dari hasil wawancara kepada narasumber antara pemilik lahan dan penyewa lahan. Teori ilmiah yang digunakan merujuk pada rukun dan syarat akad ijarah. Implementasi sewa lahan pertanian yang diterapkan di Desa Garung yakni pertama, bentuk pelaksanaan sewa lahan pertanian dilakukan secara tertulis atau saling percaya. Pada akad ijarah terdapat rukun dalam sewa lahan pertanian. Berdasarkan dari rukun akad ijarah tersebut menyatakan bahwa tidak ada penjelasan terkait dengan pelaksanaaan perjanjian sewa lahan pertanian yang harus dilakukan secara tertulis atau secara lisan. Pelaksanaan perjanjian sewa lahan pertanian yang dilakukan secara lisan di Desa Garung sudah memenuhi rukun dalam akad ijarah, karena terdapat pelaksanaan ijab dan qabul yang menunjukkan adanya suatu kerelaan antara kedua pihak.

Kedua, Penanggung modal dan biaya pelaksanaan penggarapan lahan pertanian akan ditanggung sepenuhnya oleh penyewa lahan pertanian, sedangkan pemilik lahan akan memperoleh ujrah dari penyewa lahan. Pelaksanaan sewa lahan pertanian di Desa Garung menggunakan sistem tahunan yang dilakukan tiga kali penanaman dalam satu tahunnya, yaitu musim rendeng akan ditanami padi, musim marengan akan ditanami padi (gaduh) dan musim ketigo akan ditanami jagung atau tembakau, sedangkan untuk tebu dalam pemanenannya dipanen satu tahun sekali. Hukum Islam pelaksanaan sewa lahan pertanian sudah sesuai dengan akad ijarah.

Ketiga, Ujrah dibayarkan secara tahunan dalam bentuk uang sesuai dengan jangka waktu perjanjian serta ujrah akan diberikan pada saat pelaksanaan awal perjanjian sewa lahan pertanian. Penentuan ketetapan harga dapat dilihat dari luas lahan pertanian, hasil perolehan panen setiap tahunnya dan harga umum sewa yang ada di Desa Garung. Berdasarkan pendapat imam syafi'I dan ahmad terkait pembayaran sewa harus dibayarakan ketika akad. Pada sewa lahan pertanian yang dilakukan di Desa Garung dalam penetapan ujrah sudah sesuai dengan hukum islam. Adapun 
Ninit,: Lease Agreement; Well-being; Agricultural land.

pembayaran ujrah dari masing-masing narasumber yang melakukan sewa lahan pertanian.

Tabel 1. Pembayaran Ujrah Setiap Penyewa Lahan Pertanian

\begin{tabular}{cllll}
\hline Informan & Pemilik Lahan & Jumlah Uang & Penyewa Lahan & Jumlah Uang \\
\hline 1 & Bu Suma'iyah & Rp. 3.000 .000 & Bpk Juwadi & Rp. 3.000 .000 \\
\hline 2 & Bpk Juwadi & Rp. 20.000.000 & Bpk Prayitno & Rp. 20.000.000 \\
\hline 3 & Bpk Eko Heri & Rp. 10.000 .000 & Bu Siti Julaikah & Rp. 10.000 .000 \\
\hline 4 & Bu Sulastri & Rp. 6.750 .000 & Bu Painem & Rp. 6.750 .000 \\
\hline 5 & Bpk Jupri & Rp. 20.000.000 & Bpk Pamilu Hadi & Rp. 18.400.000 \\
\hline 6 & Bpk Kasdi & Rp. 15.000.000 & Bpk Basori & Rp. 15.000.000 \\
\hline 7 & Bpk Asmuri & Rp. 5.000.000 & Bpk Anwar & Rp. 5.000 .000 \\
\hline 8 & Bpk Kebi & Rp. 12.000.000 & Bpk Suwoto & Rp. 12.000.000 \\
\hline
\end{tabular}

Sumber: Data Primer yang diolah

Data tabel tersebut dapat diketahui bahwa terdapat 8 Informan yang membayar ujrah lahan pertanian berbeda-beda dan dapat dinyatakan bahwa jawaban antara pemilik lahan dengan penyewa lahan terkait jumlah ujrah yang diberikan kepada pemilik lahan jawabnya sama. Namun ada 1 informan yang menjawab berbeda karena tidak mencatat detail nominal yang telah disepakati sehingga informasi yang didapatkan dari wawancara tidak sesuai antara kedua pihak.

Keempat, terdapat jangka waktu dalam sewa lahan pertanian yang ditentukan oleh kedua pihak. Menurut pendapat ulama syafi'iyah mengatakan bahwa dalam melakukan sewa lahan pertanian harus ada batas waktu yang jelas. Pelaksanaan sewa lahan pertanian dengan demikian sudah sesuai dengan aturan hukum Islam. Adapun tahun dan lamanya pelaksanaan melakukan sewa lahan pertanian di Desa Garung:

Tabel 2. Tahun Pelaksanaan dan Lamanya Sewa Lahan Pertanian

\begin{tabular}{|c|c|c|c|c|c|c|}
\hline No & Pemilik Lahan & $\begin{array}{l}\text { Tahun } \\
\text { Sewa }\end{array}$ & $\begin{array}{l}\text { Laha } \\
\text { Sewa }\end{array}$ & Penyewa Lahan & $\begin{array}{c}\text { Tahun } \\
\text { Sewa }\end{array}$ & $\begin{array}{l}\text { Lama } \\
\text { Sewa }\end{array}$ \\
\hline 1 & Bu Suma'iyah & $2010-2015$ & 5 tahun & Bpk Juwadi & \multicolumn{2}{|c|}{ 2010-2015 5 tahun } \\
\hline 2 & Bpk Juwadi & 2013-2023 & 10 tahun & Bpk Prayitno & \multicolumn{2}{|c|}{ 2014-2023 10 tahun } \\
\hline 3 & Bpk Eko Heri & $2015-2020$ & 5 tahun & Bu Siti Julaikah & \multicolumn{2}{|c|}{ 2016-2020 5 tahun } \\
\hline 4 & Bu Sulastri & 2019-2033 & 15 tahun & Bu Painem & \multicolumn{2}{|c|}{ 2020-2034 15 tahun } \\
\hline 5 & Bpk Jupri & $2016-2023$ & 8 tahun & Bpk Pamilu Hadi & \multicolumn{2}{|c|}{ 2013-2022 8 tahun } \\
\hline 6 & Bpk Kasdi & 2019-2020 & 2 tahun & Bpk Basori & \multicolumn{2}{|c|}{ 2019-2020 2 tahun } \\
\hline 7 & Bpk Asmuri & 2018-2022 & 5 tahun & Bpk Anwar & \multicolumn{2}{|c|}{ 2018-2023 5 tahun } \\
\hline 8 & Bpk Kebi & $2015-2020$ & 6 tahun & Bpk Suwoto & \multicolumn{2}{|c|}{ 2015-2020 6 tahun } \\
\hline
\end{tabular}


Data tabel tersebut dapat lihat bahwa terdapat 8 informan yang melakukan sewa lahan pertanian dengan tahun yang berbeda-beda. Hal ini dapat diketahui antara jawaban kedua pihak dalam menjawab pertanyaan terkait tahun pelaksanaan dan lamanya pelaksanaan sewa lahan pertanian di Desa Garung jawabnya sama. Namun ada 5 informan yang menjawab berbeda dikarenakan tidak mencatat detail tahun pelaksanaan yang telah disepakati sehingga informasi yang didapatkan dari wawancara tidak sesuai antara kedua pihak.

Dampak Implementasi Akad Ijarah bagi Peningkatan Kesejahteraan Petani Terhadap Pelaku Pemilik lahan dan Penyewa Lahan Pertanian di Desa Garung

Dampak implementasi akad ijarah pada peningkatan kesejahteraan petani di Desa Garung dapat diketahui dengan menggunakan teori ilmiah yang menjadi rujukan indikator kesejahteraan dari nilai-nilai islam yaitu indikator Maqashid Syariah. Beberapa indikator kesejahteraan petani yang diukur menggunakan Maqashid Syariah yaitu pertama peningkatan kesejahteraan pada indikator Agama yang dirasakan oleh petani pemilik lahan dan penyewa lahan dari segi kerohanian para petani melakukan kegiatan amal jariyah seperti zakat, sedekah dari perolehan hasil sewa lahan pertanian, disamping itu akan memperoleh pahala meskipun orang itu sudah meninggal dunia akan tetapi pahala tersebut akan tetap mengalir. Pada saat wawancara yang digunakan dalam indikator kesejahteraan kerohanian meliputi sedekah dan zakat. Berikut ini diagram batang dampak implementasi akad ijarah bagi peningkatan kesejahteraan petani yang dirasakan oleh pelaku pemilik lahan dan penyewa lahan di Desa Garung dalam indikator agama. 


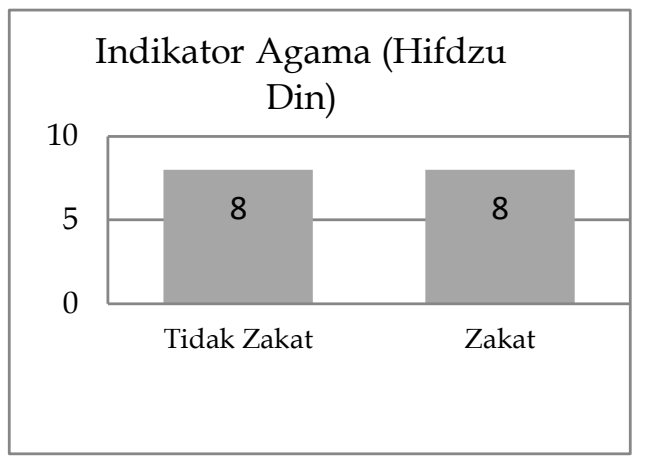

Gambar 2. Amal Jariyah Zakat

Sumber: Data Primer yang diolah

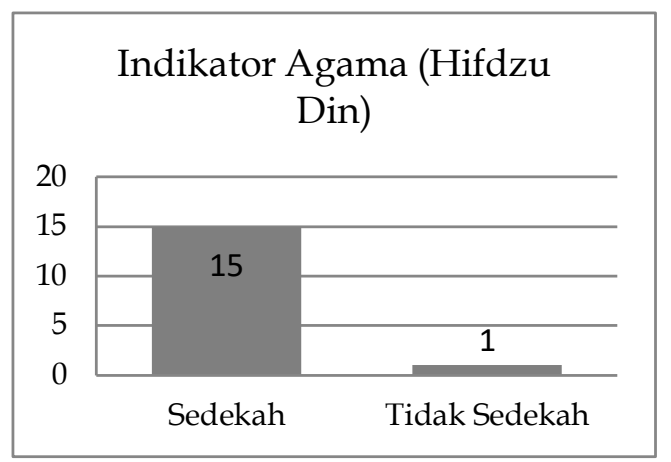

Gambar 3. Amal Jariyah Sedekah

Sumber: Data Primer yang diolah sPada diagram barang tersebut dapat dilihat bahwa peningkatan kesejahteraan indikator Agama dalam kemampuan melakukan amalan zakat sama-sama setara yaitu hasil uang sewa dari 8 pemilik lahan tidak dapat meningakatkan aspek kerohanian pada amal jariyah zakat karena mereka menyewakan lahan untuk kebutuhan mendesak, sedangkan 8 penyewa lahan dari hasil panen dapat meningkatkan aspek kerohanian mereka dalam berzakat. Selain itu kemampuan melakukan amal sedekah dari 15 orang antara kedua pihak dapat meningkatkan amalan sedekah sebagian perolehan uang sewa pemilik lahan yang diberikan kepada orang tua yang sudah jompo, masjid dan pondok, sedangkan sebagian hasil panen penyewa lahan dari 1-2 sak gabah akan diberikan kemasjid dan pondok. Akan tetapi terdapat 1 orang pemilik lahan tidak dapat meningkatkan amalan zakat karena hasil uang sewa tersebut untuk kebutuhan modal usaha simpan pinjam.Kedua, Peningkatan kesejahteraan pada indikator jiwa dapat diukur dari terpenuhinya hasil uang sewa dan hasil panen untuk kebutuhan kesehatan oleh pelaku sewa lahan pertanian di Desa Garung. Berikut ini diagram batang pada dampak implementasi akad ijarah bagi peningkatan kesejahteraan petani yang dirasakan oleh pelaku pemilik lahan dan penyewa lahan di Desa Garung.dalam indikator jiwa. 


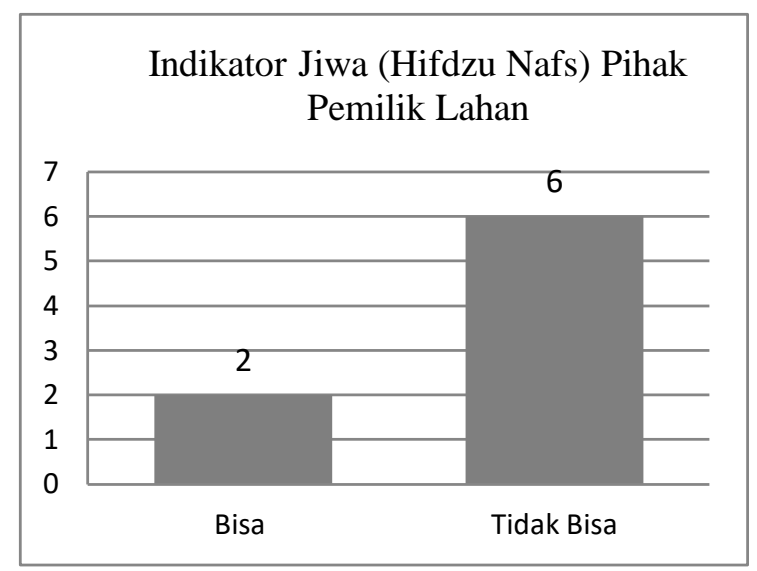

Gambar 4. Terpenuhi Kesehatan

Pemilik Lahan

Sumber: Data Primer yang diolah

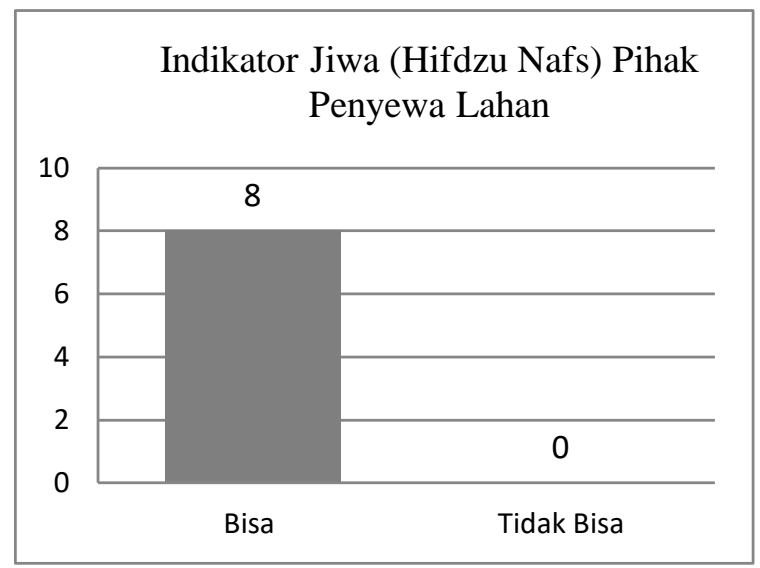

Gambar 5 Terpenuhi Kesehatan

Penyewa Lahan

Sumber: Data Primer yang diolah

Data diagram batang tersebut dapat diketahui bahwa 6 pemilik lahan merasa hasil dari uang sewa tidak cukup untuk memenuhi kebutuhan kesehatan seperti membeli obat dan berobat kedokter. Akan tetapi 2 orang merasa hasil uang sewa dapat membeli obat, sedangkan dari 8 penyewa lahan hasil dari panennya dapat mencukupi untuk kebutuhan kesehatan. Bahwa dari pemilik lahan tidak dapat meningkatkan kesejahteraan jiwa dalam pemenuhan kebutuhan kesehatan karena hasil dari uang sewa tersebut digunakan untuk kebutuhan yang lain. Sedangkan dari penyewa lahan hasil panen dapat meningkatkan kebutuhan kesehatan dengan cara menjual sebagian gabah mereka untuk berobat.

Ketiga, Peningkatan kesejahteraan pada indikator akal dapat dilihat dari segi peningkatan terhadap pengetahuan atau pemahaman petani pelaku sewa lahan pertanian di Desa Garung terkait pertanian. Berikut grafik dampak implementasi akad ijarah bagi peningkatan kesejahteraan petani yang dirasakan oleh pelaku kedua pihak pada indikator akal. 


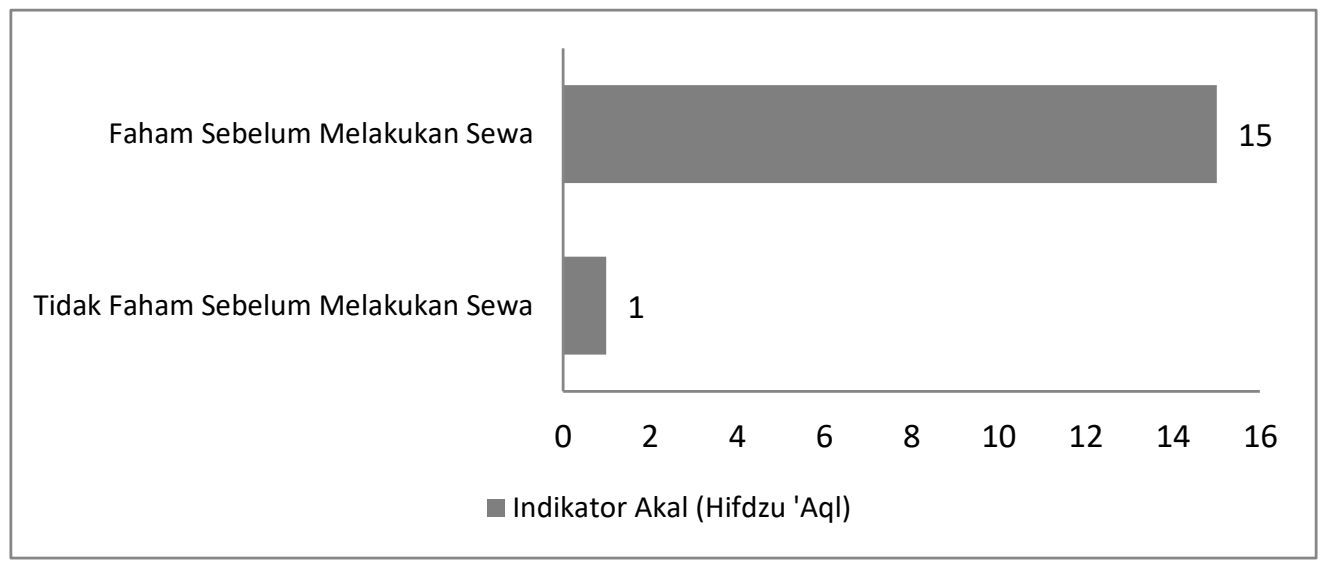

Gambar 6. Tingkat Pengetahuan Dalam Melakukan Sewa Sumber: Data Primer yang diolah

Pada data grafik tersebut dapat diketahui bahwa sebelum melakukan sewa terdapat 1 orang yang tidak faham tentang pengetahuan terkait pertanian karena belum terjun langsung dan tidak memiliki sawah, sedangkan sebelum melakukan sewa terdapat 15 orang antara pemilik lahan dan penyewa lahan sudah faham terkait pertanian karena mereka sebelum melakukan sewa lahan, mereka bekerja sebagai buruh tani dan mengerjakan lahannya sendiri. Kesejahteraan pada indikator akal dapat meningkat karena setelah melakukan sewa lahan mereka lebih memahami terkait dengan pertanian. Pengetahuan yang dimaksud seperti memahami cara penanaman dan memanen yang baik dan benar, cara mengatasi hama, cara mengetahui kualitas padi, jagung, tembakau, dan tebu yang bagus, dan mengatahui sewa lahan pertanian harus dilakukan dengan saling jujur, saling terbuka, serta saling percaya satu sama lain.

Keempat, Peningkatan kesejahteraan pada indikator keturunan diukur dari terpenuhinya hasil uang sewa dan hasil panen untuk kebutuhan biaya pendidikan anak-anak pelaku sewa lahan pertanian di Desa Garung. Berikut diagram lingkatan dampak implementasi akad ijarah bagi peningkatan kesejahteraan petani yang dirasakan oleh pelaku kedua pihak di Desa Garung dalam indikator keturunan. 


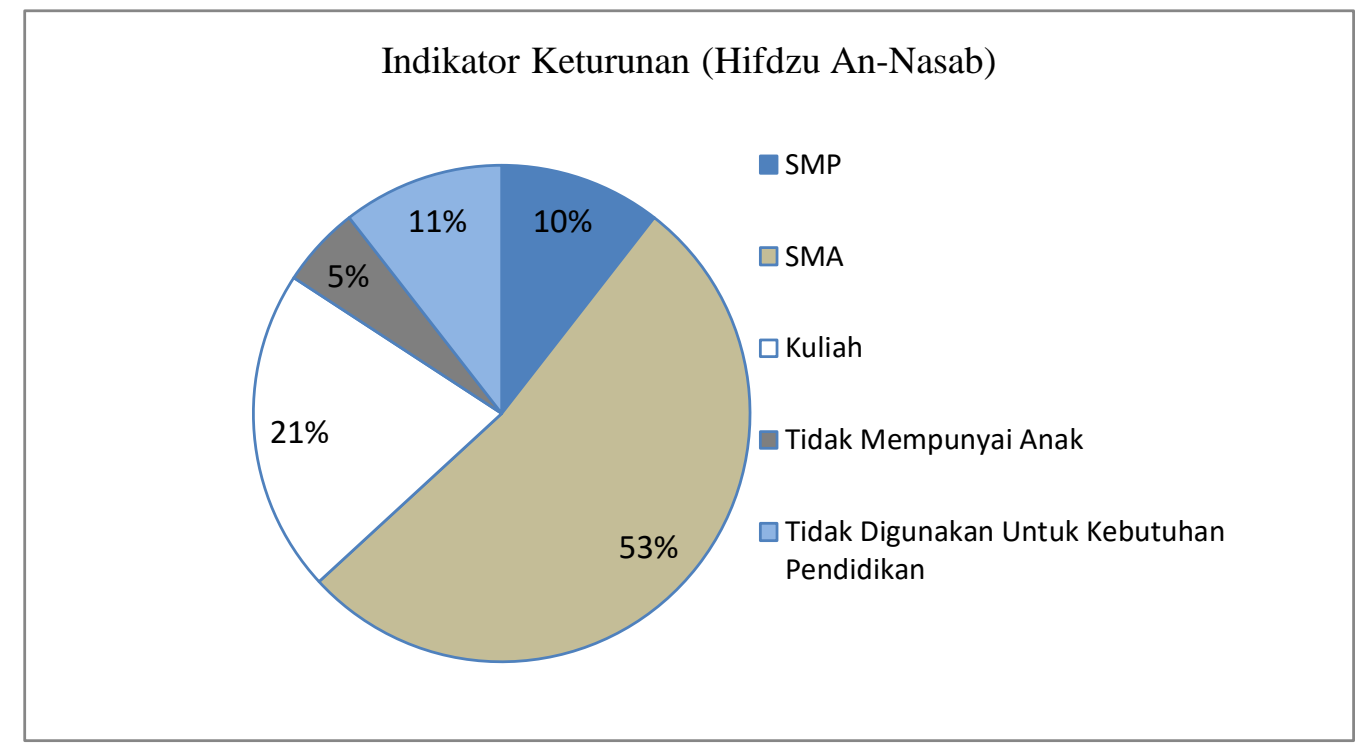

Gambar 7. Terpenuhinya Tingkat Pendidikan Anak Sumber: Data Primer yang diolah

Pada diagram lingkaran dilihat bahwa hasil uang sewa dari pemilik lahan dan hasil perolehan panen dari penyewa lahan dapat digunakan untuk biaya pendidikan anak petani pelaku sewa lahan pertanian. Data diatas menunjukkan 53\% untuk biaya sekolah SMA, 21\% untuk biaya kuliah, $11 \%$ dari pemilik lahan yang ditidak dipergunakan untuk biayai sekolah anaknya karena uang hasil sewa dipergunakan untuk kebutuhan yang lain, 10\% untuk biaya sekolah SMP, dan 5\% dari pemilik lahan yang tidak memiliki anak. Dapat dipahami bahwa kesejahteraan indikator keturunan dapat terpenuhi dengan adanya hasil sewa lahan pertanian.

Kelima, Peningkatan kesejahteraan pada indikator harta dapat melihat dari peningkatan penghasilan petani pelaku sewa lahan pertanian di Desa Garung dengan cara melihat perolehan penghasilan sewa lahan pertanian. Berikut diagram batang pada peningkatan kesejahteraan petani dalam indikator harta. 


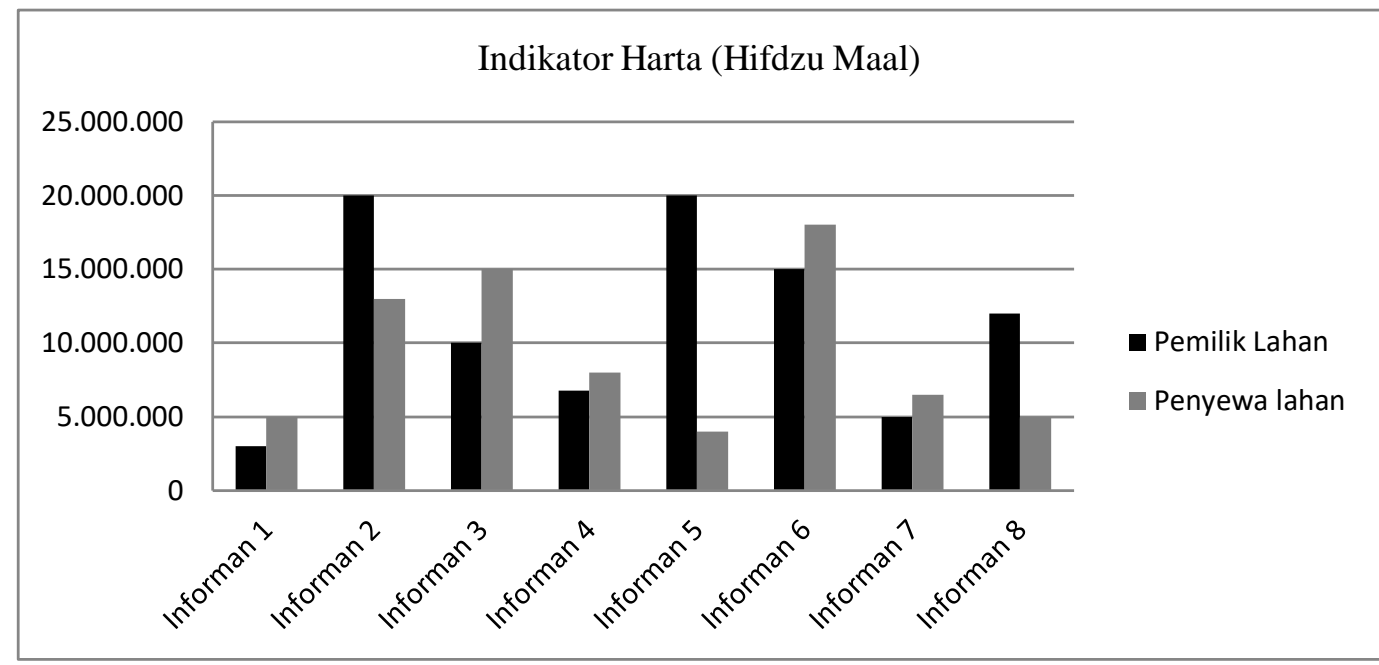

Gambar 8 Peningkatan Pendapatan Petani

Sumber: Data Primer yang diolah

Diagram batang tersebut dapat dilihat bahwa hasil perolehan sewa lahan kedua pihak dapat meningkatkan kesejahteraan pada indikator harta karena dengan jumlah uang perolehan bagi pemilik lahan dan penyewa lahan dapat dipergunakan untuk memenuhi kebutuhan yang mereka inginkan.

\section{KESIMPULAN}

Berdasarkan hasil dari penelitian yang dilakukan oleh peneliti terkait implementasi akad ijarah pada sektor pertanian serta dampak bagi peningkatan kesejahteraan petani di Desa Garung, dapat disimpulkan bahwa penerapan sewa lahan pertanian di Desa Garung sudah sesuai dengan hukum Islam dalam akad ijarah, sedangkan dari segi peningkatan kesejahteraan petani bagi pemilik lahan dilihat dari indikator agama dan jiwa tidak dapat meningkat karena mereka menyewakan lahan pertanian dengan tujuan membutuhkan uang untuk membeli kebutuhan yang diinginkan. Namun bagi penyewa lahan dilihat dari indikator agama, jiwa, akal, keturunan, dan harta, dapat meningkatkkan kesejahteraan petani. Hal ini menunjukkan bahwa penerapan sewa lahan pertanian di Desa Garung dapat membantu perekonomian penduduk desa walaupun terdapat perbedaan dari bebebrapa informan antara kedua pihak dalam menjawab pertanyaan tentang biaya ujrah, tahun awal pelaksanaan dan berakhirnya perjanjian dikarenakan tidak mencatat secara detail hal-hal yang penting dari pelaksanaan perjanjian sewa lahan pertanian. 


\section{DAFTAR PUSTAKA}

Alitawan, A. A. I., \& Sutrisna, K. (2017). Faktor-Faktor yang Mempengaruhi Pendapatan Petani Jeruk pada Desa Gunung Bau Kecamatan Kintamani Kabupaten Bangli. E-Jurnal Ekonomi Pembangunan Universitas Udayana, 6(5), 798.

Amalia, L. N. (2015). Tinjauan Ekonomi Islam Terhadap Penerapan Akad Ijarah Pada Bisnis Jasa Laundry. Economic: Jurnal Ekonomi Dan Hukum Islam, 5(2), 170.

Badan Pusat Statistik. (2020). Luas Panen dan Produksi Padi di Indonesia 2019. Retrieved from Berita Resmi Statistik website: https://www.bps.go.id/pressrelease/download.html?nrbvfeve=MTc1Mg $\% 3 D \% 3 D \& s d f s=l d j f d i f s d j k f a h i \& t w o a d f n o a r f e a u f=M j A y M C 0 w M i 0 y N S A x$ MzoyNjozMg\%3D\%3D

Badan Pusat Statistik Provinsi Jawa Timur. (2019). Rata-Rata Luas Lahan yang Dikuasai Rumah Tangga Usaha Petanian Menurut Kabupaten/Kota dan Jenis Lahan (m2) 2018. Retrieved from Badan Pusat Statistik Provinsi Jawa Timur website: https://jatim.bps.go.id

Badan Pusat Statistik Provinsi Jawa Timur. (2020). Luas Panen dan Produksi Padi di Provinsi Jawa Timur 2019.

Fawa'id, M. W., \& Huda, N. (2020). Praktik Sewa Lahan Pertanian di Masyarakat Perspektif Hukum Ekonomi Islam. EI-Faqih : Jurnal Pemikiran Dan Hukum Islam, 6(1), 38-39.

Isbah, U., \& Iyan, R. Y. (2016). Analisis Peran Sektor Pertanian Dalam Perekonomian dan Kesempatan Kerja di Provinsi Riau. Jurnal Sosial Ekonomi Pembangunan, 7(19), 45-46.

Nasution, M. S. A., \& Nasution, R. H. (2020). Filsafat Hukum Islam \& Maqashid Syariah (Cet. Ke-1). Jakarta: Kencana.

Nugraha, J. P. (2016). Sistem Muzara'ah Sebagai Alternatif Pembiayaan Pertanian di Indonesia. IQTISHODIA : Jurnal Ekonomi Syariah, 1(2), 82.

Oktafia, R. (2016). Integrasi Sistem Resi Gudang (SRG) Dengan Lembaga Keuangan Mikro Syariah (LKMS) Untuk Meningkatkan Permodalan Bisnis Pertanian Melalui Kelompok Tani. Jurnal Agribisnis Dan Pengembangan Ekonomi Perdesaan III, 3, 299. 
Ninit,: Lease Agreement; Well-being; Agricultural land.

Rachmat, M. (2013). Nilai Tukar Petani : Konsep, Pengukuran dan Relevansinya sebagai Indikator Kesejahteraan Petani. Jurnal Forum Penelitian Agro Ekonomi, 31(2), 112. https:/ / doi.org/10.21082/fae.v31n2.2013.111-122

Ridho, M. (2017). Pandangan Islam Tentang Kesejahteraan Sosial Bagi Kelompok Penyandang Disabilitas. Jurnal Al-Bayan, 23(1), 110.

Santoso, H., \& Anik. (2015). Analisis Pembiayaan Ijarah Pada Perbankan Syariah. Jurnal Ilmiah Ekonomi Islam, 1(2), 110-111.

Setiawan, F. (2015). Al-Ijarah Al-A'mal Al-Mustarakah Dalam Perspektif Hukum Islam. Jurnal DINAR, 1(2), 104-105.

Sholihin, K., Ami' in, S. N., \& Lestari, P. (2019). Maqashid Shariah Sebagai Alat Ukur Kinerja Bank Syariah Telaah Konsep Maqasid Sharia Index (MSI) AsySyatibi. Laa Maisyir, 6(2), 151.

Sugiyono. (2018). Metode Penelitian Kualitatif, Kuantitatif, dan RED (Cet. Ke-27). Bandung: Alfabeta.

Suhendi, H. (2016). Fiqh Muamalah (Cet. Ke-10). Jakarta: PT. Raja Gafindo Persada.

Suratha, K. (2015). Krisis Petani Berdampak Pada Ketahanan Pangan di Indonesia. Jurnal Media Kominikasi Geografi, 16(1), 67-68.

Umam, K. (2013). Manajemen Perbankan Syariah (Cet. Ke-1). Bandung: CV. Pustaka Setia.

Utomo, S. J., \& Wulandari, D. (2020). Sistem Sewa Lahan Pertanian Masyarakat Perdesaan Dalam Perspektif Ekonomi. Jurnal Dinamika Ekonomi Pembangunan ( JDEP ), 3(1), 269. 